\title{
1 Seasonal variability of multiple leaf traits captured by 2 leaf spectroscopy at two temperate deciduous forests
}

4 Xi Yang ${ }^{1,2}$, Jianwu Tang ${ }^{2}$, John F. Mustard ${ }^{1}$, Jin $\mathrm{Wu}^{3,5}$, Kaiguang Zhao ${ }^{4}$, 5 Shawn Serbin ${ }^{5}$, Jung-Eun Lee ${ }^{1}$

7 1. Department of Earth, Environment, and Planetary Sciences, Brown University, 8 Providence, RI, 02912, USA

9 2. The Ecosystems Center, Marine Biological Laboratory, Woods Hole, MA, 02543, 10 USA

11 3. Department of Ecology and Evolutionary Biology, University of Arizona, Tucson, AZ, 12 85721, USA

13 4. School of Environment and Natural Resources, Ohio Agricultural and Research

14 Development Center, The Ohio State University, Wooster, OH 44691, USA

15 5. Environmental \& Climate Sciences Department, Brookhaven National Laboratory, 16 Upton, NY, 11973, USA

19 Keywords: phenology, leaf physiology, foliar chemistry, carbon cycle, chlorophyll,

20 carotenoids, nitrogen, leaf mass per area, partial least square regression (PLSR), sun and

21 shaded leaves 


\section{Abstract}

32 Understanding the temporal patterns of leaf traits is critical in determining the seasonality

33 and magnitude of terrestrial carbon, water, and energy fluxes. However, we lack robust

34 and efficient ways to monitor the temporal dynamics of leaf traits. Here we assessed the

35 potential of leaf spectroscopy to predict and monitor leaf traits across their entire life

36 cycle at different forest sites and light environments (sunlit vs. shaded) using a weekly

37 sampled dataset across the entire growing season at two temperate deciduous forests. The

38 dataset includes field measured leaf-level directional-hemispherical

39 reflectance/transmittance together with seven important leaf traits [total chlorophyll

40 (chlorophyll a and b), carotenoids, mass-based nitrogen concentration $\left(\mathrm{N}_{\text {mass }}\right)$, mass-based

41 carbon concentration $\left(\mathrm{C}_{\text {mass }}\right)$, and leaf mass per area (LMA)]. All leaf traits varied

42 significantly throughout the growing season, and displayed trait-specific temporal

43 patterns. We used a Partial Least Square Regression (PLSR) modeling approach to

44 estimate leaf traits from spectra, and found that PLSR was able to capture the variability

45 across time, sites, and light environments of all leaf traits investigated $\left(\mathrm{R}^{2}=0.6 \sim 0.8\right.$ for

46 temporal variability; $\mathrm{R}^{2}=0.3 \sim 0.7$ for cross-site variability; $\mathrm{R}^{2}=0.4 \sim 0.8$ for variability from

47 light environments). We also tested alternative field sampling designs and found that for

48 most leaf traits, biweekly leaf sampling throughout the growing season enabled accurate

49 characterization of the seasonal patterns. Compared with the estimation of foliar pigments,

50 the performance of $\mathrm{N}_{\text {mass }}, \mathrm{C}_{\text {mass }}$ and LMA PLSR models improved more significantly

51 with sampling frequency. Our results demonstrate that leaf spectra-trait relationships vary

52 with time, and thus tracking the seasonality of leaf traits requires statistical models

53 calibrated with data sampled throughout the growing season. Our results have broad 
54 implications for future research that use vegetation spectra to infer leaf traits at different 55 growing stages. 
1. Introduction

57 Leaf traits are important indicators of plant physiology and critical components in

58 numerous ecological processes (Kattge et al. 2011; Wright et al. 2004). For example,

59 Leaf chlorophyll concentration represents the light harvesting potential and is an

60 indicator of photosynthetic activity (Niinemets 2007; Laisk et al. 2009), while accessory

61 pigments such as carotenoids protect leaves from damage when exposed to excessive

62 sunlight (Demmig-Adams and Adams 2000). Leaf mass per area (LMA) describes plants'

63 investment to leaves in terms of carbon and nutrients to optimize sunlight interception

64 (Poorter et al., 2009). Carbon is one of the major elements in cellulose and lignin, which

65 are used to build the cell walls of various leaf tissues (Kokaly et al. 2009). Nitrogen is the

66 key element in both carbon fixation enzyme RuBisCO and chlorophyll (Evans 1989,

67 1989b), and thus plays an important role in modeling leaf and canopy photosynthesis

68 (Bonan et al. 2012). The aforementioned leaf traits, as well as the corresponding spectral

69 properties, strongly depend on leaf developmental stages and light environments (Yang et

70 al. 2014; Lewandowska and Jarvis 1977; Poorter et al. 2009; Wilson et al. 2000; Wu et al.,

71 2016). Thus, capturing the spatial and temporal variations of these leaf traits is important

72 for understanding terrestrial ecosystem functioning (Schimel et al. 2015).

73 Despite the importance and increasing interests in the temporal and spatial

74 variability of these (and many other) leaf traits, the capacity to monitor these traits over

75 seasons has not progressed accordingly. Wet chemical analysis of these leaf traits is

76 considered to be the standard method, yet the destructive and time-consuming protocols

77 do not allow for rapid and repeated sampling of some traits. On the other hand, field

78 spectroscopy can augment traditional approaches, and allows for repeated sampling of the

79 same leaves and thus tracking time-sensitive changes such as frost damage (Asner and 
80 Martin 2008; Couture et al., 2013; Serbin et al. 2014). Although spectroscopic

81 approaches are promising, many previous efforts have only focused on mature sunlit

82 leaves (e.g., Asner and Vitousek 2005; Ustin et al. 2004; Wicklein et al. 2012; but see

83 Sims and Gamon (2002)) and have not explored the ability of leaf spectral properties to

84 track the continuous and developmental changes of leaf traits throughout the growing

85 season. The temporal dimension of the spectra-trait relationship has mostly focused on

86 leaf chlorophyll concentration (Belanger et al. 1995; Dillen et al. 2012; Shen et al. 2009),

87 while it is largely unknown for other important leaf traits like nitrogen, carbon, and

88 LMA. Moreover, the availability of high temporal resolution ( weekly) datasets on

89 important leaf traits and spectra is limited. These data would be very useful for assessing

90 the utility of leaf spectral properties (i.e. reflectance) for estimating the temporal

91 variability of leaf traits, as well as scaling to broader regions and informing process

92 modeling activities.

93 Leaf traits not only change with time, but also with the light environments, such

94 as moving from sun-lit to shaded light conditions and the commensurate changes in

95 microclimate which also affect leaf traits (Ellsworth and Reich 1993; Niinemets, 2007,

96 Wu et al., 2016b), as a consequence of underlying fundamental evolutionary and eco-

97 physiological constraints (Terashima et al. 2001). For example, shaded leaves display

98 lower chlorophyll a to b ratio and higher LMA compared with sunlit leaves (Niinemets,

99 2007). This variation in the vertical domain can be as much as the trait variation across

100 space (Serbin et al., 2014). As such, it is important to not only explore trait variation

101 across sites but also as in the vertical canopy light gradients to better capture ecosystem

102 responses to global change. 
Three categories of methods to estimate leaf traits from leaf spectral properties

104 (i.e., reflectance and transmittance) are spectral vegetation indices (SVIs), statistical

105 inversion methods exploiting the full wavelength $(400-2500 \mathrm{~nm})$, and leaf radiative

106 transfer models like PROSPECT (Jacquemoud and Baret 1990), which are limited to only

107 a few leaf traits (do not include carbon and nitrogen) and thus are not the focus of this

108 study. SVIs are typically calculated using the reflectance from two or three wavelengths

109 (Huete et al. 2002; Richardson et al. 2002; Sims and Gamon 2002). With proper

110 calibration across a diverse range of vegetation types, SVIs can yield relatively robust

111 models (Féret et al. 2011). Statistical methods such as Partial Least Square Regression

112 (PLSR) modeling have become more popular in recent decades with the availability of

113 high spectral resolution observations and increasing computational power (Asner and

114 Martin 2008; Couture et al. 2013; Wold et al. 2001). Although both being widely used,

115 these methods have not been thoroughly assessed, especially with respect to the

116 robustness of PLSR models across time and different light environments (but see Serbin

117 et al., 2014).

118 Here our primary goal was to assess the ability of leaf optical properties to track

119 temporal variability of a suite of leaf traits across sites and different light environments.

120 To explore this we collected a dataset of $\sim$ weekly-sampled leaf traits [including total

121 chlorophyll (and chlorophyll a and b), carotenoids, mass-based nitrogen concentration

$122\left(\mathrm{~N}_{\text {mass }}\right)$, mass-based carbon concentration $\left(\mathrm{C}_{\text {mass }}\right)$, and LMA] along with in situ

123 directional-hemispherical reflectance/transmittance during the growing season at two

124 temperate deciduous forests. We first present the temporal variations of leaf traits and

125 spectra, and then highlight the ability of leaf spectra to track temporal variability of leaf 
126 traits. We investigate the robustness of the PLSR across season, sites, and light

127 environments. We further explore the optimal field sampling strategy. We conclude by

128 discussing the broad implications of our study.

130 2. Study area and methods

$131 \quad 2.1$. Study sites

Our field sampling was conducted in two temperate deciduous forests located in

133 the northeastern United States. The first site, on the island of Martha's Vineyard (MV,

$13441.362 \mathrm{~N}, 70.578 \mathrm{~W}$ ), is a white oak (Quecus alba) dominated forest with a stand age of

135 80-115 years after natural recovery from abandoned cropland and pasture (Foster et al.

136 2002). Mean annual temperature is $10^{\circ} \mathrm{C}$, and annual precipitation is about $1200 \mathrm{~mm}$

137 from 1981 to 2010 (Yang et al. 2014). The second site, in Harvard Forest (HF, 42.538N,

$13872.171 \mathrm{~W}$ ), has two dominating deciduous tree species: red oak (Quercus rubra) and red

139 maple (Acer rubrum), with a few scattered yellow birch (Betula alleghaniensis). The

140 forest age is $70-100$ years. The annual mean temperature is about $7.5^{\circ} \mathrm{C}$ (Wofsy et al.

141 1993), and the annual precipitation is $1200 \mathrm{~mm}$. Remote sensing studies suggested that

142 the start of season in Martha's Vineyard was about 10-20 days later than that of HF

143 (Fisher and Mustard 2007; Yang et al. 2012).

144 2.2. Measurements of leaf spectral properties and traits

145 We conducted two field campaigns to collect leaf traits at the sites in Martha's

146 Vineyard and Harvard Forest, respectively. In 2011, weekly (biweekly in August)

147 sampling of leaves throughout the growing season (June - November) was conducted at

148 the Martha's Vineyard site on three white oak trees. For each sampling period, we cut 
149 two fully sunlit branches (each having 6 leaves) and one shaded branch using a tree

150 pruner. The spectral properties of the leaves were immediately measured (see below).

151 Then the leaves were placed in a plastic bag containing a moist paper towel, and all the

152 samples were kept in a cooler filled with ice until being transferred back to the lab for

153 further measurements. In 2012, the same weekly (biweekly from mid-July to late August)

154 measurements in Harvard Forest were made on five individuals (two red oaks, two red

155 maples and one yellow birch) from May to October. For each tree, two sunlit and one

156 shaded branch were collected each time.

157 Directional-hemispherical leaf reflectance and transmittance were measured

158 immediately after the sampling using a spectroradiometer (ASD FS-3, ASD Inc. Boulder,

159 CO, USA; spectral range: $300-2500 \mathrm{~nm}$, spectral resolution: $3 \mathrm{~nm} @ 700 \mathrm{~nm}, 10$

160 nm@1400/2100 nm) and an integrating sphere (ASD Inc.). The intensity of light source

161 in the integrating sphere decreases sharply beyond $2200 \mathrm{~nm}$, with the signal in 2200-2500

$162 \mathrm{~nm}$ being noisy (ASD Inc., personal communications), and thus is excluded from the

163 spectral-leaf traits analysis below.

164 The measured leaf traits include total chlorophyll concentration (including

165 chlorophyll a and chlorophyll $\left.\mathrm{b}, \mu \mathrm{g} / \mathrm{cm}^{2}\right)$, carotenoids $\left(\mu \mathrm{g} / \mathrm{cm}^{2}\right)$, leaf mass per area (LMA,

$\left.166 \mathrm{~g} / \mathrm{m}^{2}\right)$, nitrogen concentration by mass $\left(\mathrm{N}_{\text {mass }}, \%\right)$, and carbon concentration by mass

$167\left(\mathrm{C}_{\text {mass }}, \%\right)$. Each branch was divided into two subsets. One subset was used to measure

168 pigment concentrations. To measure the chlorophyll and carotenoids concentration, three

169 leaf discs $\left(\sim 0.28 \mathrm{~cm}^{2}\right.$ each) were taken from each leaf using a hole puncher, and then

170 ground in a mortar with $100 \%$ acetone solution and $\mathrm{MgO}$ (Asner et al. 2009). After an 8-

171 minute centrifugation, the absorbance of the supernatant was measured using a 
172 spectrophotometer (Shimadzu UV-1201, Kyoto, Japan). Chlorophyll a, b and carotenoids

173 concentrations were calculated using the readings from 470, 520, 645, 662 and $710 \mathrm{~nm}$

174 (Lichtenthaler and Buschmann 2001). The other subset (3 leaves) was scanned using a

175 digital scanner (EPSON V300, EPSON, Long Beach, CA, USA), and oven-dried (65 C)

176 for at least 48 hours for quantification of leaf dry mass. LMA was calculated based on the

177 following equations:

$$
L M A=W_{d r y} / A_{\text {leaf }}
$$

179 where $W_{d r y}$ is leaf dry mass weight, $A_{\text {leaf }}$ is the leaf area calculated from the scanned leaf 180 using ImageJ (Schneider et al. 2012). Dried leaves were then ground and analyzed for

$181 \mathrm{~N}_{\text {mass }}$ and $\mathrm{C}_{\text {mass }}$ with a CHNS/O analyzer (FLASH 2000, Thermo Scientific, Waltham, 182 MA, USA).

183 2.3. Methods to estimate leaf traits using leaf spectral properties

184 We used two categories of methods to estimate leaf traits based on leaf spectral 185 properties: vegetation indices that utilize the reflectance from two wavelengths, and 186 statistical methods that exploit the information from the full leaf spectrum.

187 Based on extensive datasets from various types of biomes and plants, Féret et al.

188 (2011) established polynomial relationships between SVIs and total chlorophyll

189 concentration, carotenoids and LMA (Table 1). We also obtained the best estimate of a, b,

190 and c using our own dataset (see below for the division between training and validation

191 dataset).

192 Table 1 Simple Vegetation Indices (SVI) used in this study. These indices were 193 calibrated using extensive datasets (Féret et al. 2011). Leaf traits were calculated based 194 on a polynomial relationship: leaf trait $=\mathrm{a} \times$ index $^{2}+\mathrm{b} \times$ index $+\mathrm{c}$.

\begin{tabular}{lll}
\hline Leaf traits & Index & Coefficients \\
\hline
\end{tabular}




\begin{tabular}{|c|c|c|c|c|}
\hline & & $\mathbf{a}$ & b & c \\
\hline $\begin{array}{c}\mathrm{Chl} \\
\left(\mu \mathrm{g} / \mathrm{cm}^{2}\right)\end{array}$ & $\left(\mathrm{R}_{780}-\mathrm{R}_{712}\right) /\left(\mathrm{R}_{780}+\mathrm{R}_{712}\right)$ & 40.65 & 121.88 & -0.77 \\
\hline $\begin{array}{c}\text { Car } \\
\left(\mu \mathrm{g} / \mathrm{cm}^{2}\right)\end{array}$ & $\left(\mathrm{R}_{800}-\mathrm{R}_{530}\right) /\left(\mathrm{R}_{800}+\mathrm{R}_{530}\right)$ & 8.09 & 11.18 & -0.38 \\
\hline $\begin{array}{c}\text { LMA } \\
\left(\mathrm{g} / \mathrm{cm}^{2}\right)\end{array}$ & $\left(\mathrm{R}_{1368}-\mathrm{R}_{1722}\right) /\left(\mathrm{R}_{1368}+\mathrm{R}_{1722}\right)$ & -0.1004 & 0.1286 & -0.0044 \\
\hline
\end{tabular}

195

196

197 regression models between leaf spectra and leaf traits (Zhao et al. 2013):

198

199 where $\mathbf{y}$ is an n-by-1 matrix of leaf traits (n equals to the number of leaf samples). $\mathbf{X}$ is an

200 n-by-m matrix (m equals the number of bands from each spectrum, and thus in this study

$201 \mathrm{~m}=1801$ : from 400 to $2200 \mathrm{~nm}$ ). $\varepsilon$ is the n-by-1 estimation error that is to be minimized.

202 PLSR modeling can be used to develop the best model for the given dataset while avoid 203 over-fitting (Asner and Martin 2008; Serbin et al. 2014). The numbers of independent

204 factors used in the regression were determined by minimizing the Prediction Residual 205 Error Sum of Squares (PRESS).

206 The above leaf traits and spectra from two sites were combined as one single

207 dataset. To test the effectiveness of PLSR on this dataset, the whole dataset is divided 208 into two parts (70\%-30\%), for the training and validation of PLSR, respectively. We used 209 the Kennard-Stone algorithm to select the training subset that provides a uniform 210 coverage of the whole dataset (Kennard and Stone 1969). The training dataset was used 211 to optimize the regression model parameters $(\boldsymbol{\beta})$, and then the validation dataset was used 
212 to test and evaluate the PLSR models. Evaluation statistics include the $\mathrm{R}^{2}$, Root Mean

213 Square Error (RMSE) and normalized RMSE (NRMSE), which is the RMSE divided by

214 the range of the estimated leaf traits.

215 The relative importance of reflectance or transmittance at each wavelength is

216 determined by calculating the values of variable importance on projection (VIP) (Wold et

217 al. 2001). VIP is an indicator of the importance of each wavelength for the modeling of 218 both leaf traits $(\mathbf{y})$ and spectra $(\mathbf{X})$. Higher absolute values indicate greater importance of

219 the corresponding wavelength. Generally, wavelengths with VIP value larger than 1 are

220 considered being important (Mehmood et al. 2012).

To examine the robustness of PLSR models across time, light environment, and

224 sites, we designed the following scenarios. In all scenarios, we used leaf traits and spectra

225 of a subset of the whole dataset (e.g., leaf samples that are collected during only a certain

226 period of time, or a certain level of light environment) to train PLSR models, and tested

227 the performance of the models against the whole dataset.

228 For this we created five scenarios to examine how the timing of leaf sampling

229 affects predictability of seasonality of leaf traits. Leaf traits and spectra in the first three

230 scenarios were sampled only for the spring, summer, and fall, respectively. We defined

231 these three seasons based on variations in total chlorophyll concentration: days before

232 total chlorophyll reached a plateau in the mid-season were defined as spring; days when

233 total chlorophyll started to decrease were defined as fall; and between spring and fall,

234 days were defined as summer. The last two scenarios were that leaf traits and spectra 
235 were sampled monthly or biweekly (instead of weekly as in the full dataset). We then use

236 the PLSR trained with leaf samples in the above scenarios to predict the leaf traits of the

237 entire dataset. There are two reasons to choose the whole dataset for validation: 1) the

238 whole dataset captures the temporal variability of leaf traits, which is the goal of this test;

239 2) it is necessary to have the same validation dataset to compare the performance of these

240 five scenarios. Performance of these sampling strategies was measured by calculating the

$241 \quad$ RMSE and $\mathrm{R}^{2}$.

242 Finally, we also explored our capacity to develop a generalized approach for

243 capturing seasonality in leaf traits with spectral observations. Two tests were conducted

244 to examine the robustness of PLSR models at different light environment and sites. Test 1

245 used sunlit leaf traits and spectra to train a PLSR model, which was then used to predict

246 shaded leaf traits with corresponding spectra. We then switched the training and

247 validation datasets so that shaded leaves were used to train PLSR model while sunlit

248 leaves were used to validate. Test 2 divided the entire dataset into two subsets by

249 geographic location. For example, we used Martha's Vineyard dataset to calibrate the

250 model, and Harvard Forest dataset to validate, and vice versa.

251 3. Results

252 3.1. Temporal and spatial variability of leaf traits

253 All leaf traits displayed significant temporal variations throughout the growing 254 seasons (Fig.1 and 2). Overall, pigments from both sites displayed similar bell-shaped 255 trajectories, despite being sampled from different species and locations within the 256 canopy. Chlorophyll concentration rapidly increased from $\sim 10 \mu \mathrm{g} / \mathrm{cm}^{2}$ at the beginning of

257 the season, and then stabilized around $\sim 50 \mu \mathrm{g} / \mathrm{cm}^{2}$ and $\sim 40 \mu \mathrm{g} / \mathrm{cm}^{2}$ in Martha's Vineyard 
258 and Harvard Forest, respectively, during the summer followed by a decline in the fall to 259 values similar to the beginning of the season prior to leaf abscission. The Harvard Forest 260 samples were collected from three different species, and showed much larger variability 261 compared with Martha's Vineyard, especially for the shaded leaves (Fig.1 e-h). The 262 carotenoids concentration was $\sim 3 \mu \mathrm{g} / \mathrm{cm}^{2}$ at the beginning/end of the season and $\sim 10$ $263 \mu \mathrm{g} / \mathrm{cm}^{2}$ at the peak season. The total chlorophyll concentration relative to the carotenoids 264 concentration (Chl/Car) increased during the early seasons. In the fall, though both 265 chlorophyll and carotenoids decreased, Chl/Car decreased steadily, as a result of faster 266 decline of chlorophyll relative to the carotenoids (Fig. S1a). 

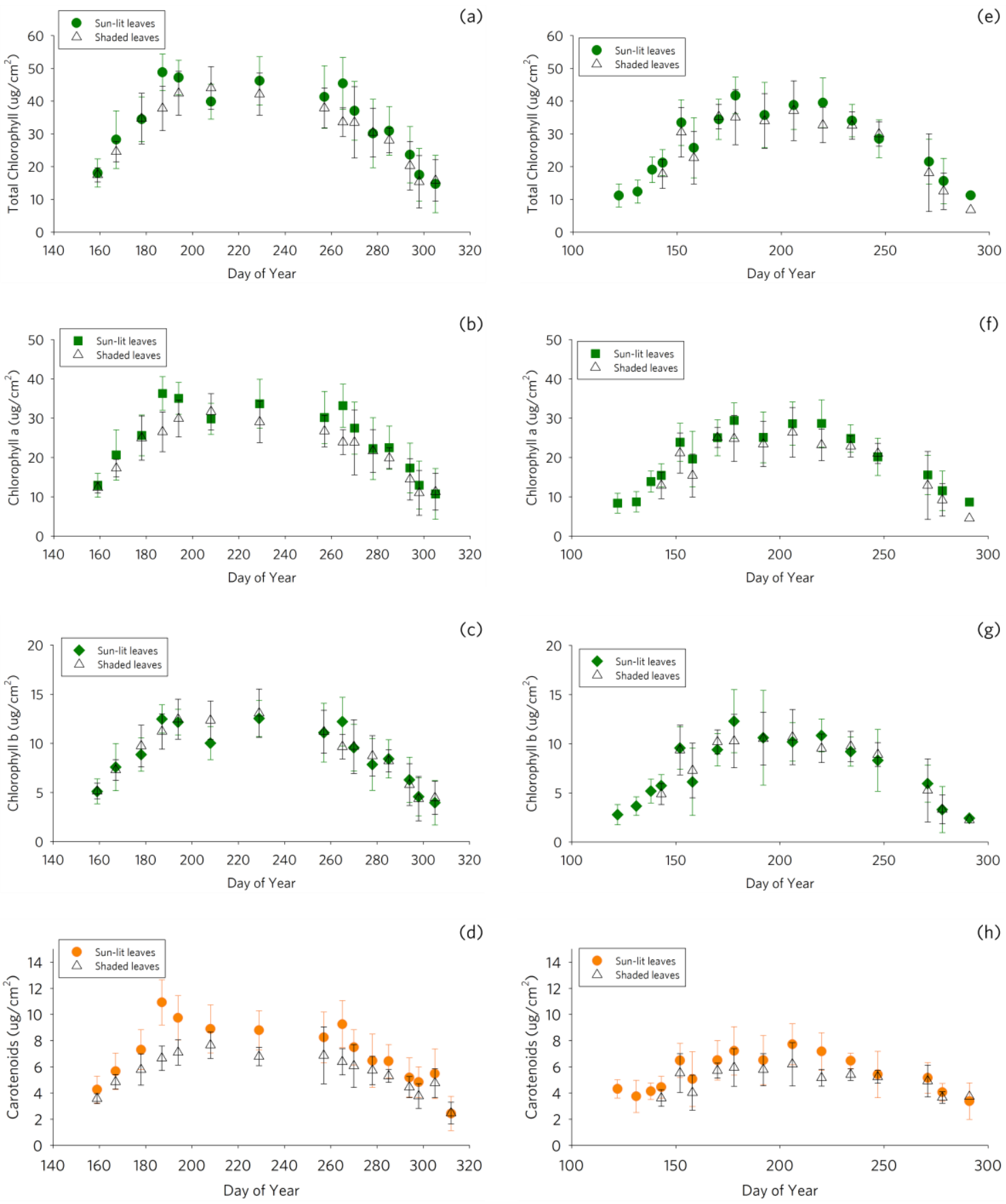

269 Figure 1 Seasonal patterns of pigments of sunlit (filled) and shaded (open) leaves from 270 two deciduous forests. Martha's Vineyard, year 2011: (a) Total chlorophyll; (b) chlorophyll a; (c) chlorophyll b; (d) carotenoids. Harvard Forest year 2012: (e) Total chlorophyll; (f) chlorophyll a; (g) chlorophyll b; (h) carotenoids. Each dot is the mean value of all the samples collected that day. Error bars are standard deviations. 

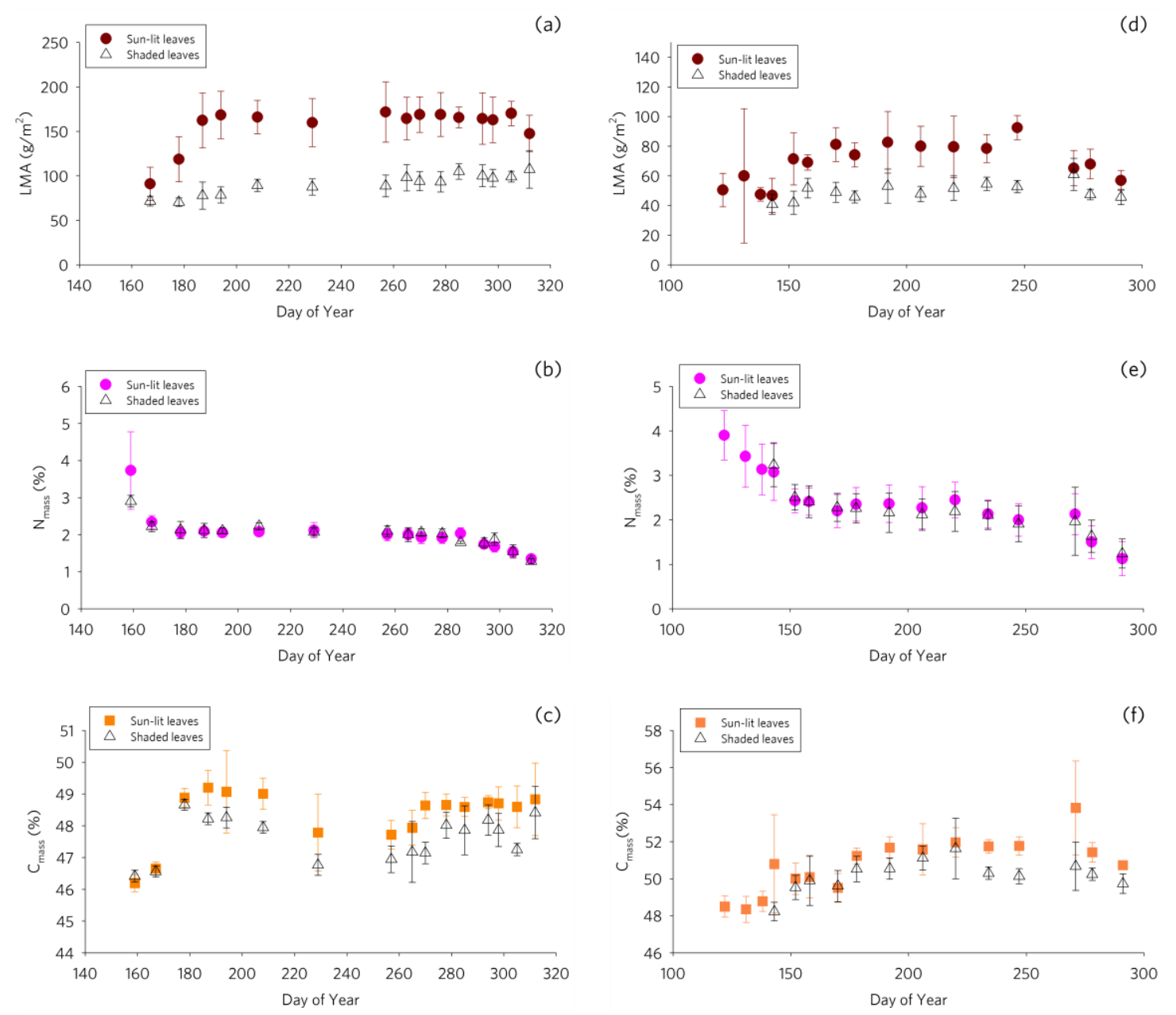

276 Figure 2 Seasonal patterns of biochemical and biophysical properties of sunlit (filled symbols) and shaded (open symbols) leaves from two deciduous forest sites. Martha's 278 Vineyard, year 2011: (a) Leaf mass per area (LMA); (b) mass-based nitrogen concentration $\left(\mathrm{N}_{\text {mass }}\right)$; (c) mass-based carbon concentration $\left(\mathrm{C}_{\text {mass }}\right)$. Harvard Forest, year 280 2012: (d) LMA; (e) $\mathrm{N}_{\text {mass }}$; (f) $\mathrm{C}_{\text {mass. }}$ Each dot is the mean value of all the samples 281 collected that day. Error bars are standard deviations.

282 The remaining three leaf traits (LMA, $\mathrm{N}_{\text {mass }}$, and $\mathrm{C}_{\text {mass }}$ ) displayed different 283 seasonal patterns compared with leaf pigments (Fig. 2). For example, LMA rapidly 284 increased in the spring, but showed only a minor decline by the end of the measurement 285 period. $\mathrm{N}_{\text {mass }}$ was higher ( 4-5\%) at the start of the season, and remained stable around $2 \%$ 286 during the summer, followed by $\sim 1 \%$ decrease in the fall, presumably caused by nitrogen 287 resorption (Eckstein et al. 1999). Similar to LMA, $\mathrm{C}_{\text {mass }}$ accumulated 2-4\% in the spring 
288 and stabilized for the rest of the growing seasons around 50\%. The rapid increase of

289 LMA in the spring was accompanied by a similar increase of $\mathrm{C}_{\text {mass }}$ and decrease of $\mathrm{N}_{\text {mass }}$,

290 which all ended at the same time (DOY 194 in Martha's Vineyard, and DOY $\sim 170$ in

291 Harvard Forest).

292 Mean annual values of leaf traits from Martha's Vineyard were significantly

293 different from those at Harvard Forest (Table 2). For example, leaf chlorophyll in

294 Martha's Vineyard is $5.64 \mu \mathrm{g} / \mathrm{cm}^{2}(17.5 \%)$ higher than that from Harvard Forest ( $\mathrm{p}<$

295 0.0001). LMA in Martha's Vineyard showed much larger variation than that from

296 Harvard Forest, and the mean LMA was $39.85 \mathrm{~g} / \mathrm{m}^{2}$ (37.5\%) higher than that from

297 Harvard Forest. Similar situation applies to all other leaf traits except for $\mathrm{C}_{\text {mass }}$, for which

298 the value at Harvard Forest were higher than that at Martha's Vineyard.

299 Sunlit leaves contained more total chlorophyll and carotenoids (Fig. S2) and the

300 carotenoids to the total chlorophyll ratio was significantly higher for sun-lit leaves

301 comparing with shaded leaves (MV, $p<0.0001$; HF, $p=0.0182$ ). Chlorophyll a/b was

302 also significantly larger for sunlit leaves in both sites (MV, $p<0.0001$; HF, $p<0.0001$ ).

303 Similarly, LMA and $\mathrm{C}_{\text {mass }}$ values were significantly higher in the sun-lit leaves versus

304 shaded foliage, with the only exception of $\mathrm{N}_{\text {mass }}$, in which both sun-lit and shaded leaves

305 were indistinguishable throughout the two seasons (Fig. 2b). 


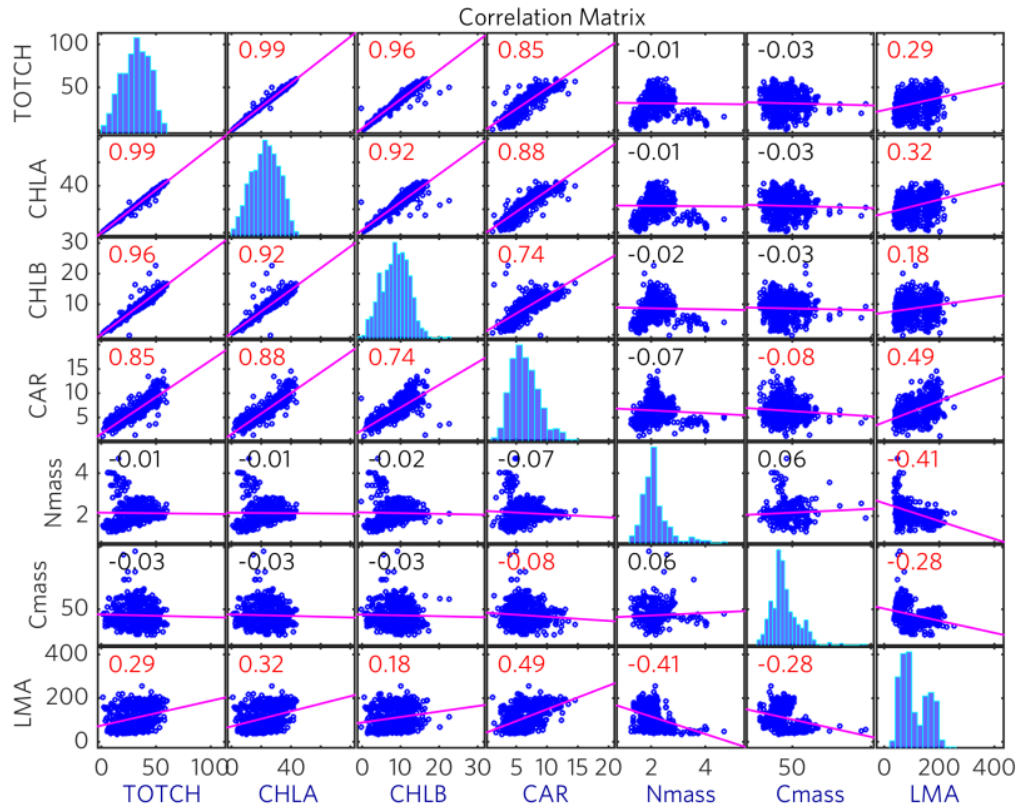

307 Figure 3 Correlation matrix of all the leaf traits. Histograms of each leaf traits are on the 308 diagonal positions. Number on each subplot indicates $R^{2}$ (Red means $\left.p<0.05\right)$. See Table 3092 for units.

310 Table 2 Annual mean values and standard deviation of leaf traits at two sites: MV, 311 Martha's Vineyard, and HF, Harvard Forest (stars indicate the p-values of t-test between 312 the values of leaf traits from two sites: ***: $\mathrm{p}<0.0001 ; * *: \mathrm{p}<0.01 ; *: \mathrm{p}<0.05)$.

Leaf traits Units MV HF

\begin{tabular}{cccc}
\hline Total Chl **** & $\mu \mathrm{g} / \mathrm{cm}^{2}$ & $31.74(12.17)$ & $26.19(9.29)$ \\
Chl a ** & $\mu \mathrm{g} / \mathrm{cm}^{2}$ & $23.19(8.81)$ & $18.92(6.70)$ \\
Chl b** & $\mu \mathrm{g} / \mathrm{cm}^{2}$ & $8.70(3.31)$ & $7.48(2.73)$ \\
Car $_{* *}$ & $\mu \mathrm{g} / \mathrm{cm}^{2}$ & $6.16(2.28)$ & $5.59(1.33)$ \\
$\mathbf{N}_{\text {mass }} * *$ & $\%$ (unitless) & $2.17(0.50)$ & $2.03(0.50)$ \\
$\mathbf{C}_{\text {mass }} * * *$ & $\%$ (unitless) & $48.34(1.24)$ & $51.12(0.87)$ \\
LMA $* * *$ & $\mathrm{~g} / \mathrm{m}^{2}$ & $106.29(45.04)$ & $66.44(15.56)$
\end{tabular}


A linear regression analysis highlighted various levels of correlation among leaf

315 traits (Fig. 3). Close correlation was found among leaf pigments: total chlorophyll

316 concentration was highly correlated with carotenoids concentration $\left(\mathrm{R}^{2}=0.85\right)$,

317 suggesting a tight coupling among those pigments throughout the growing season despite

318 the faster decrease of chlorophyll concentration during the senescence (Fig. S1). For the

319 entire dataset (across all sunlit and shaded leaves from different species), $\mathrm{N}_{\text {mass }}$ was

320 weakly correlated with pigments. LMA showed positive correlation with all pigments

321 while a negative correlation was observed with $\mathrm{N}_{\text {mass }}$ and $\mathrm{C}_{\text {mass. }}$

322

323 3.2. Seasonal variability of leaf spectral properties

324 The full leaf reflectance and transmittance spectrum showed significant variability

325 in both amplitude and shape (Fig.4). The visible (VIS, $400-700 \mathrm{~nm}$ ) and near infrared

326 (NIR, 700-1000 nm) changed dramatically throughout the season, while shortwave

327 infrared (SWIR, 1000-2500 nm) was relatively stable. Data from Martha's Vineyard

328 showed larger variability in NIR compared to Harvard Forest. 

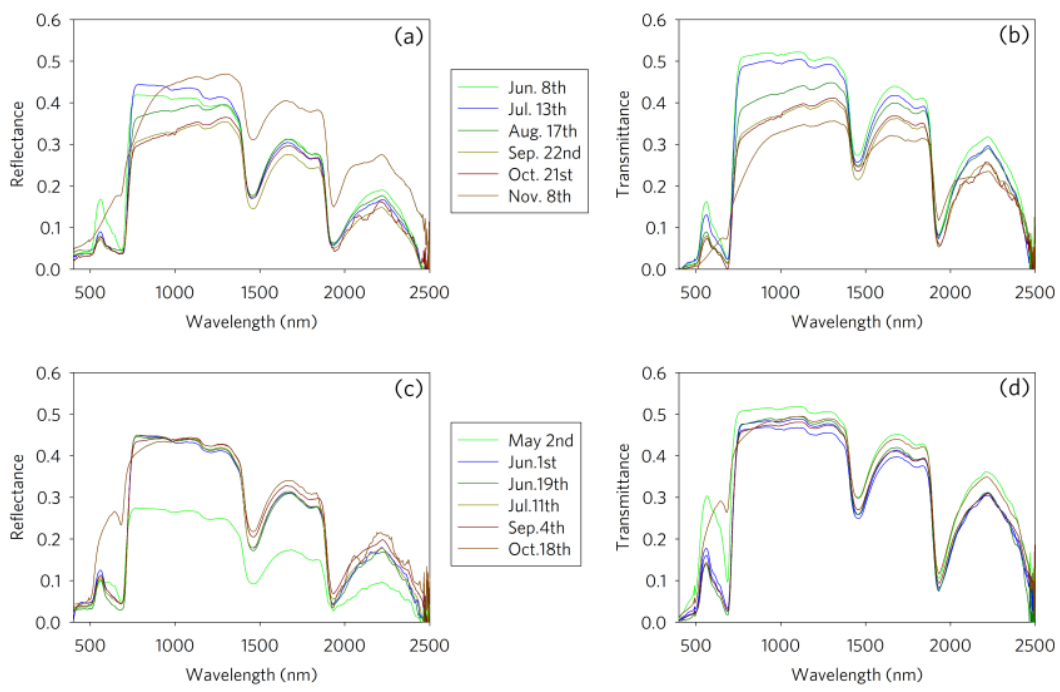

330 Figure 4 Examples of leaf directional-hemispherical reflectance and transmittance 331 measured on (a, b) Martha's Vineyard and in (c,d) Harvard Forest.

332 The R, G, and B reflectance at both sites showed a U-shape pattern (Fig. S3a,

333 S3c): all of them decreased in the beginning of the season; and increased in the end of the

334 season after a stable summer. The NIR from Martha's Vineyard showed a consistent

335 decline in the mid-summer and then increased in the fall, while the NIR from Harvard

336 Forest was relatively stable throughout the season. Leaf transmittance at each band had

337 similar patterns as the reflectance (Fig. S3b, S3d).

338 3.3. Comparisons of methods of leaf traits estimation

339 We compared two categories of methods to estimate leaf traits from leaf spectra.

340 Overall, PLSR consistently outperformed the SVIs in estimating leaf traits, showing an

341 improved performance when the SVIs were trained by the original datasets or our own

342 dataset (Table 3). The PLSR models using leaf reflectance (PLSR ref $_{\text {hereafter) had }}$

343 slightly better performance compared with those using leaf transmittance (PLSR tra

344 hereafter) when assessed with the independent dataset. For different leaf traits, the

345 performance of these methods varied, as described in details below. 
347 (Fig.5. $\mathrm{R}^{2}>0.70$ and NRMSE $<10 \%$ ). The SVI for chlorophyll showed slightly larger 348 prediction error $\left(\sim 0.5 \mu \mathrm{g} / \mathrm{cm}^{2}\right.$ larger) compared with $\operatorname{PLSR}_{\text {ref }}$ and $\operatorname{PLSR}_{\text {tra }}$ (Table 3$)$. The

349 two components of chlorophyll ( $\mathrm{Chl}$ a and b) were also well captured by the PLSR ref

350 approach with NRMSE less than $10 \%$ and $\mathrm{R}^{2}$ of 0.73 and 0.66 respectively. Similarly,

351 carotenoids were estimated relatively well by PLSR $\mathrm{ref}_{\text {ef }}$ and $\mathrm{PLSR}_{\text {tra }}\left(\mathrm{R}^{2}>0.65\right)$ but the SVI

352 for carotenoids had 30\% higher RMSE comparing with PLSR $\mathrm{ref}_{\text {. }}$

$353 \quad \mathrm{~N}_{\text {mass }}$ was well captured by leaf spectra especially with the reflectance dataset

354 (Fig.5. $\mathrm{R}^{2}>0.6$ and NRMSE < 5\%). Similarly, both PLSR $_{\text {ref }}$ and PLSR $_{\text {tra }}$ explained $~ 60 \%$

355 of the variance in $\mathrm{C}_{\text {mass }}\left(\mathrm{R}^{2}>0.6\right.$ and NRMSE $\left.<7 \%\right)$. PLSR also displayed a strong

356 capacity to predict LMA $\left(\mathrm{R}^{2}=\sim 0.80\right.$ and NRMSE $\left.<9 \%\right)$, where the SVI for LMA could

357 not capture more than $20 \%$ of the variation in LMA and had more than double the RMSE

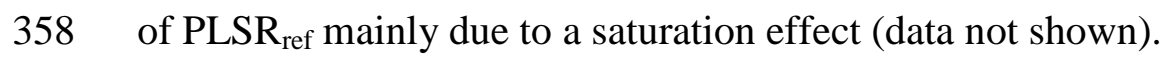


Table 3 Comparisons among methods in terms of the goodness-of-fit (RMSE, NRMSE and $\mathrm{R}^{2}$ ) for the dataset at both Martha's transmittance dataset to predict leaf traits.

\begin{tabular}{|c|c|c|c|c|c|c|c|c|}
\hline \multirow{2}{*}{$\begin{array}{l}\text { Leaf } \\
\text { traits }\end{array}$} & \multicolumn{4}{|c|}{$\begin{array}{c}\text { RMSE } \\
\text { (NRMSE) }\end{array}$} & \multicolumn{4}{|c|}{$\mathbf{R}^{2}$} \\
\hline & $\begin{array}{l}\text { Simple indices } \\
\text { (Féret et al. } \\
\text { 2011) }\end{array}$ & $\begin{array}{l}\text { Simple indices } \\
\text { (this dataset) }\end{array}$ & $\mathrm{PLSR}_{\text {ref }}$ & $\mathrm{PLSR}_{\text {tra }}$ & $\begin{array}{l}\text { Simple indices (Féret } \\
\text { et al. 2011) }\end{array}$ & $\begin{array}{l}\text { Simple indices } \\
\text { (this dataset) }\end{array}$ & PLSR $_{\text {ref }}$ & PLSR $_{\text {tra }}$ \\
\hline $\begin{array}{c}\text { Total } \\
\text { Chl } \\
\left(\mu \mathrm{g} / \mathrm{cm}^{2}\right. \\
)\end{array}$ & 5.93 & 6.04 & $\begin{array}{c}5.48 \\
(0.09)\end{array}$ & $\begin{array}{l}5.62 \\
(0.10)\end{array}$ & 0.71 & 0.71 & 0.73 & 0.64 \\
\hline $\begin{array}{c}\text { Chl a } \\
\left(\mu g / \mathrm{cm}^{2}\right. \\
)\end{array}$ & & & $\begin{array}{c}3.99 \\
(0.09)\end{array}$ & $\begin{array}{c}4.14 \\
(0.09)\end{array}$ & & & 0.73 & 0.68 \\
\hline $\begin{array}{c}\text { Chl b } \\
\left(\mu \mathrm{g} / \mathrm{cm}^{2}\right. \\
)\end{array}$ & & & $\begin{array}{c}1.62 \\
(0.07)\end{array}$ & $\begin{array}{c}1.82 \\
(0.08)\end{array}$ & & & 0.66 & 0.58 \\
\hline $\begin{array}{c}\text { Car } \\
\left(\mu \mathrm{g} / \mathrm{cm}^{2}\right. \\
)\end{array}$ & 1.53 & 1.54 & $\begin{array}{l}1.07 \\
(0.08)\end{array}$ & $\begin{array}{l}1.20 \\
(0.09)\end{array}$ & 0.39 & 0.40 & 0.71 & 0.68 \\
\hline $\begin{array}{c}\mathbf{N}_{\text {mass }} \\
(\%)\end{array}$ & & & $\begin{array}{c}0.22 \\
(0.05)\end{array}$ & $\begin{array}{c}0.24 \\
(0.05)\end{array}$ & & & 0.63 & 0.54 \\
\hline $\begin{array}{c}\mathbf{C}_{\text {mass }} \\
(\%)\end{array}$ & & & $\begin{array}{c}0.93 \\
(0.07)\end{array}$ & $\begin{array}{c}0.95 \\
(0.07)\end{array}$ & & & 0.63 & 0.71 \\
\hline $\begin{array}{c}\text { LMA } \\
\left(\mathrm{g} / \mathrm{cm}^{2}\right)\end{array}$ & 40.6 & 39.7 & $\begin{array}{l}18.11 \\
(0.08)\end{array}$ & $\begin{array}{l}19.01 \\
(0.09)\end{array}$ & 0.20 & 0.19 & 0.85 & 0.79 \\
\hline
\end{tabular}



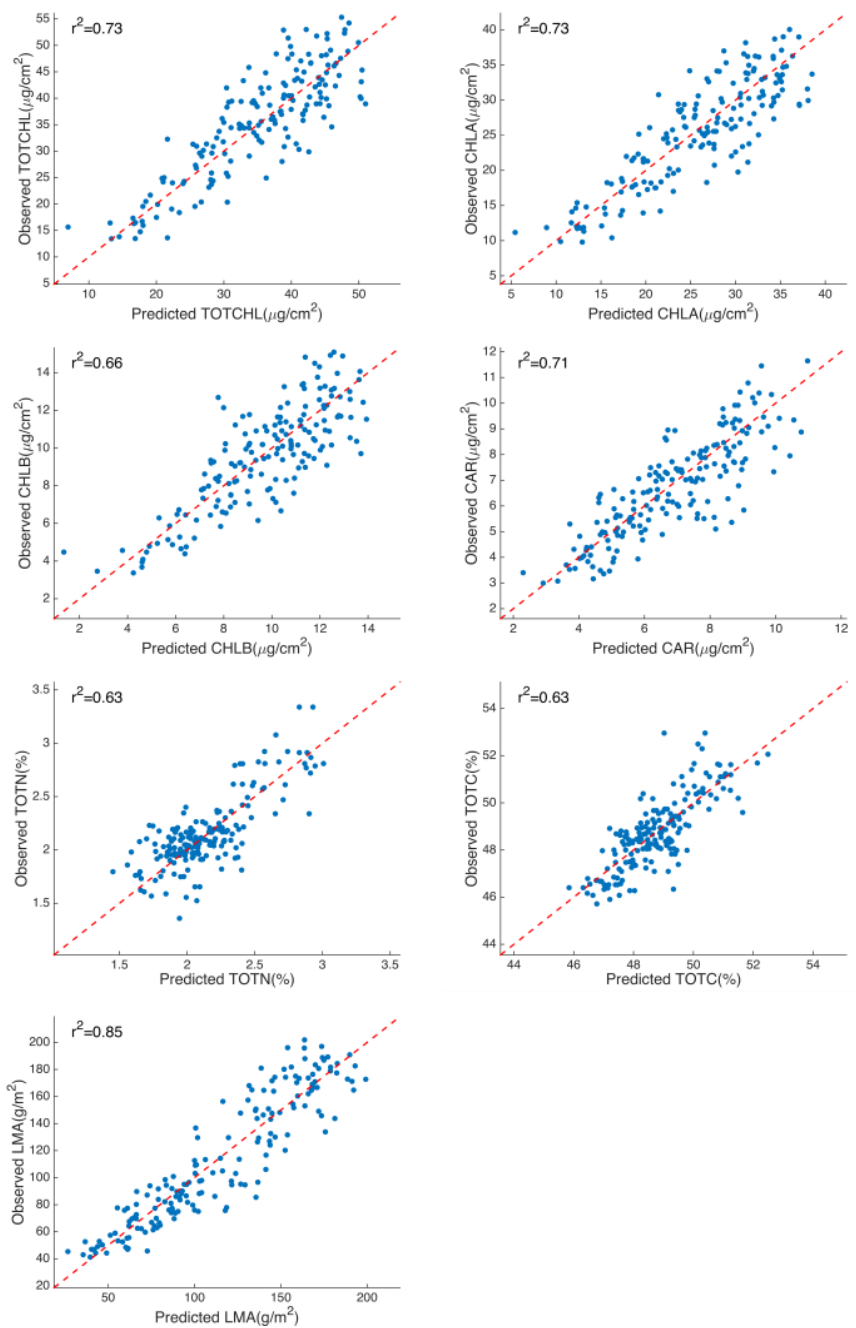

365 Figure 5 Comparisons between the observed leaf traits and predicted traits from PLSR ref. 366 For detailed statistics refer to Table 2 and 3. Observations are from the independent 367 validation dataset selected using the Kennard-Stone method. The red dashed lines are 1:1 368 line. 

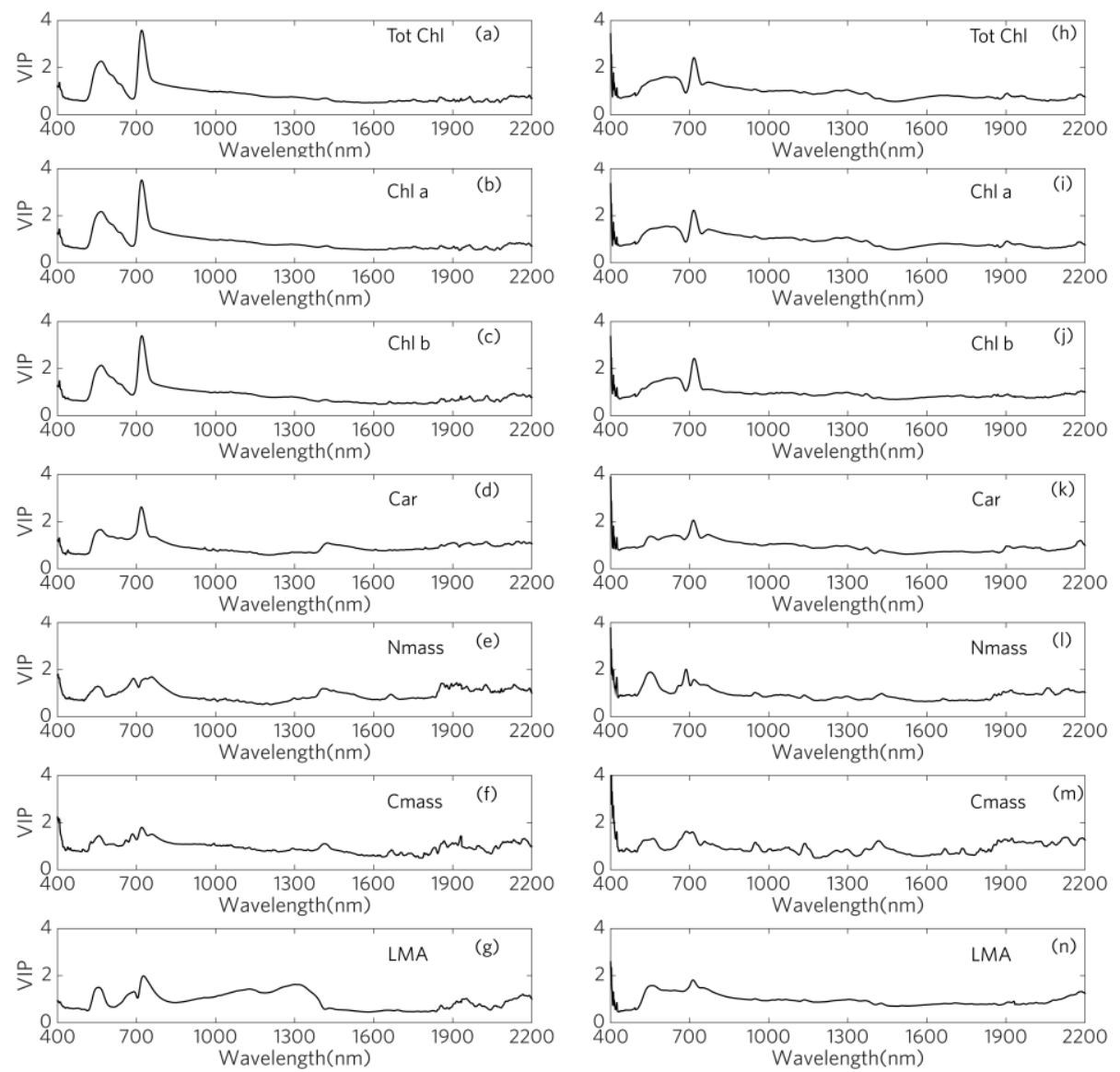

370 Figure 6 Relative importance of each wavelength in Variable Importance on Projection 371 (VIP). VIP values from PLSR ref $_{\text {and PLSR }}$ tra are on the right and left, respectively.

372 The VIP values of PLSR show the relative importance of each wavelength in

373 predicting leaf traits (Fig.6). Visible and near-infrared wavelengths were important to the

374 prediction of leaf pigments; there are three peaks (400, 550 and $730 \mathrm{~nm})$ that are related

375 to the chlorophyll absorption in the red $(620-750 \mathrm{~nm})$ and blue $(400-450 \mathrm{~nm})$, and

376 reflection in the green $(495-570 \mathrm{~nm})$. The two components of chlorophyll (a and $b)$ were

377 also mainly contributing to the red/NIR region $(600-750 \mathrm{~nm})$, and the main contributing

378 bands for chl $\mathrm{b}$ shifted towards green comparing to those for chl a (Fig. 6b and 6c) (Ustin

379 et al. 2009). Carotenoids have a similar VIP curve comparing with the chlorophyll, with

380 one distinction: the VIP values for carotenoids between $650 \mathrm{~nm}$ and $700 \mathrm{~nm}$ are relatively

381 higher to those of chlorophyll. 
383 curves. For $\mathrm{N}_{\text {mass, }}$, wavelengths around $700 \mathrm{~nm}$ and beyond $1900 \mathrm{~nm}$ are important to the

384 prediction of $\mathrm{N}_{\text {mass }}$, presumably because the visible region is controlled by pigments and

385 nitrogen is an important component in leaf pigments, and the SWIR region near $2000 \mathrm{~nm}$

386 is controlled by protein absorption features (Kokaly et al. 2009). Both $\mathrm{C}_{\text {mass }}$ and LMA

387 were related to the leaf structure and were largely contributing to the reflectance at NIR 388 and SWIR.

389 3.4. Robustness of the PLSR approach across time, sites and light environment

390 We examined the performance of the PLSR ${ }_{\text {ref }}$ models under five scenarios where 391 different sampling strategies were applied. The performance of the PLSR models 392 generally improved in the order of spring, fall, summer, monthly, and biweekly (Table 4).

393 As expected, more sampling throughout the season (and the increasing size and 394 representativeness of the calibration dataset) increased $R^{2}$ and reduced RMSE. When 395 comparing the three seasons, summer-only sampling yielded higher model performance 396 relative to the other two scenarios, yet the improvements from scenarios 2 (summer-only) 397 to scenario 4 (monthly) were not as obvious for pigments as $\mathrm{N}_{\text {mass }}, \mathrm{C}_{\text {mass }}$ and LMA. 398 Sampling scenario 5 (biweekly) largely improved the performance of PLSR, especially 399 for $\mathrm{N}_{\text {mass }}$ and $\mathrm{C}_{\text {mass }}\left(\mathrm{R}^{2}\right.$ increased from $<0.4$ to $\left.\sim 0.6\right)$.

400 Examining the seasonal patterns of predicted and observed leaf traits revealed 401 time-dependent performance of each scenario. In spring-only scenario where leaf samples 402 only from the spring were used for PLSR calibration, all leaf traits during the first four 403 weeks of the growing seasons were well estimated. However, fall season leaf traits were 404 overestimated except for LMA in Martha's Vineyard (Fig. S4m). By contrast, in the fall- 
405 only scenario, spring and summer leaf traits were underestimated except for $\mathrm{C}_{\text {mass }}$ (Fig.

406 S5k). Summer-only scenario showed a better ability to capture the seasonal patterns of

407 leaf traits, only underestimated the $\mathrm{N}_{\text {mass }}$ peak in the early spring at Harvard Forest (Fig.

408 S6j). The monthly sampling scenario improved estimation of all leaf traits, in which the

409 improvement on estimating LMA was the most obvious ( $\mathrm{R}^{2}$ from 0.26 in the summer

410 case to 0.76 in the monthly sampling case, Fig. S7m, S7n). Biweekly sampling scenario

411 appeared to produce a satisfactory result for all the leaf traits studied here (Fig. S8).

$412 \quad$ PLSR $_{\text {ref }}$ models trained using sunlit leaves explain 35\%-70\% of the variability in

413 shaded leaves with highest $\mathrm{R}^{2}$ for pigments while lowest $\mathrm{R}^{2}$ for $\mathrm{C}_{\text {mass }}$ (Fig. S9, Table $\mathrm{S} 1$ ).

414 However, PLSR ${ }_{\text {ref }}$ was less accurate for leaf traits like LMA in terms of RMSE (Fig.

$415 \mathrm{~S} 10 \mathrm{~m}$ ), for which the difference between sun-lit and shaded leaves was significant (Fig.

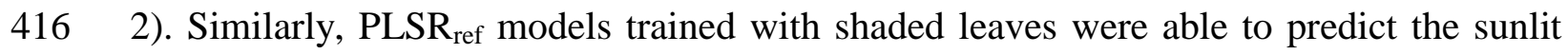

417 leaf traits, but with lower model performance compared to when trained with sunlit

418 foliage. Depending on the leaf traits, the variability explained by PLSR ranges from 35\%

419 to $70 \%$ (Fig. S10m).

$420 \quad$ PLSR $_{\text {ref }}$ models trained using data from Harvard Forest (Test 1) were able to 421 capture $60 \sim 70 \%$ of variability of the pigments from Martha's Vineyard, except for $\mathrm{N}_{\text {mass }}$ 422 and $\mathrm{C}_{\text {mass }}$ (Table 5). Similar results were obtained from PLSR ref trained using Martha's 423 Vineyard data (Test 2) and validated with Harvard Forest data. VIP values for pigments 424 in Test 1 were similar to those from Test 2. This is in stark contrast with VIP values for 425 Nmass, Cmass, and LMA from both experiments. The locations of important 426 wavelengths were quite different between two tests (Fig. S11). 
Table 4 Performance of all scenarios (spring, summer, fall, monthly, and biweekly) in terms of the goodness-of-fit (RMSE, ${ }^{2}$ )

\begin{tabular}{|c|c|c|c|c|c|c|c|c|c|c|}
\hline \multirow{2}{*}{$\begin{array}{l}\text { Leaf } \\
\text { traits }\end{array}$} & \multicolumn{5}{|c|}{ RMSE } & \multicolumn{5}{|c|}{$\mathbf{R}^{2}$} \\
\hline & Spring & Summer & Fall & Monthly & Biweekly & Spring & Summer & Fall & Monthly & Biweekly \\
\hline $\begin{array}{c}\text { Total } \\
\text { Chl } \\
\left(\mu \mathrm{g} / \mathrm{cm}^{2}\right)\end{array}$ & 8.64 & 6.64 & 7.23 & 6.32 & 5.66 & 0.60 & 0.70 & 0.72 & 0.73 & 0.77 \\
\hline$\underset{\left(\mu \mathrm{g} / \mathrm{cm}^{2}\right)}{\text { Chl a }}$ & 5.97 & 4.75 & 5.25 & 4.65 & 4.15 & 0.63 & 0.72 & 0.72 & 0.73 & 0.78 \\
\hline $\begin{array}{c}\text { Chl b } \\
\left(\mu \mathrm{g} / \mathrm{cm}^{2}\right)\end{array}$ & 2.73 & 1.92 & 2.06 & 1.89 & 1.69 & 0.48 & 0.67 & 0.69 & 0.69 & 0.73 \\
\hline $\begin{array}{c}\text { Car } \\
\left(\mu \mathrm{g} / \mathrm{cm}^{2}\right)\end{array}$ & 1.71 & 1.31 & 1.29 & 1.22 & 1.12 & 0.48 & 0.65 & 0.69 & 0.69 & 0.73 \\
\hline $\begin{array}{c}\mathbf{N}_{\text {mass }} \\
(\%)\end{array}$ & 1.62 & 0.42 & 0.51 & 0.37 & 0.29 & 0.08 & 0.36 & 0.07 & 0.36 & 0.62 \\
\hline $\begin{array}{c}\mathbf{C}_{\text {mass }} \\
(\%)\end{array}$ & 1.59 & 1.71 & 1.74 & 1.26 & 1.03 & 0.20 & 0.21 & 0.19 & 0.39 & 0.56 \\
\hline $\begin{array}{c}\text { LMA } \\
\left(\mathrm{g} / \mathrm{cm}^{2}\right)\end{array}$ & 61.13 & 27.17 & 24.86 & 21.78 & 18.76 & 0.13 & 0.71 & 0.75 & 0.79 & 0.85 \\
\hline
\end{tabular}


429 Table 5 Performance of PLSR reflectance models that were calibrated using data from one site and validated using data from the other 430 site.

\begin{tabular}{|c|c|c|c|c|}
\hline \multirow{2}{*}{$\begin{array}{l}\text { Leaf } \\
\text { traits }\end{array}$} & \multicolumn{2}{|c|}{ RMSE } & \multicolumn{2}{|c|}{$\mathbf{R}^{2}$} \\
\hline & $\mathrm{MV} \rightarrow \mathrm{HF}$ & $\mathrm{HF} \rightarrow \mathrm{MV}$ & $\mathrm{MV} \rightarrow \mathrm{HF}$ & $\mathrm{HF} \rightarrow \mathrm{MV}$ \\
\hline $\begin{array}{c}\text { Total Chl } \\
\left(\mu \mathrm{g} / \mathrm{cm}^{2}\right)\end{array}$ & 6.17 & 7.44 & 0.72 & 0.67 \\
\hline $\begin{array}{c}\text { Chl a } \\
\left(\mu \mathrm{g} / \mathrm{cm}^{2}\right)\end{array}$ & 4.39 & 5.29 & 0.73 & 0.69 \\
\hline $\begin{array}{c}\text { Chl b } \\
\left(\mu \mathrm{g} / \mathrm{cm}^{2}\right)\end{array}$ & 1.85 & 1.99 & 0.68 & 0.66 \\
\hline $\begin{array}{c}\text { Car } \\
\left(\mu \mathrm{g} / \mathrm{cm}^{2}\right)\end{array}$ & 1.19 & 1.54 & 0.59 & 0.59 \\
\hline $\mathbf{N}_{\text {mass }}(\%)$ & 0.56 & 0.72 & 0.29 & 0.20 \\
\hline $\mathbf{C}_{\text {mass }}(\%)$ & 2.89 & 2.90 & 0.10 & 0.23 \\
\hline $\begin{array}{c}\text { LMA } \\
\left(\mathrm{g} / \mathrm{cm}^{2}\right)\end{array}$ & 35.62 & 59.45 & 0.60 & 0.72 \\
\hline
\end{tabular}




\section{4. Discussion}

$434 \quad 4.1$ Can we track the seasonality of leaf traits using leaf spectroscopy?

435 Here we show that the seasonal variability of leaf traits can be well captured with

436 leaf spectroscopy approaches (Fig.5, Table 3). All leaf properties (seven leaf traits and

437 leaf spectra) display seasonal dynamics that are also related to the location and

438 microclimate (i.e., sunlit vs. shaded, and the accompanying changes in humidity and 439 temperature). The PLSR models explain $60 \%$ 80\% of variability of these leaf traits in

440 our study, supporting the hypothesis that leaf spectra can capture the seasonal variability

441 of leaf traits. Indeed, each leaf trait has its own spectral fingerprint (Curran, 1989; Kokaly

442 et al., 2009), as we have seen from the VIP values of PLSR models (Fig.6). Patterns of

443 VIP values were similar to previous studies (Asner et al. 2009; Serbin et al. 2014) and

444 consistent with our understandings of leaf physiology (Ustin et al. 2009). This is an

445 important result as collecting leaf spectra is much more time-efficient than traditional

446 approaches and allows for repeated sampling of the same leaves throughout the season.

447 SVIs can be an alternative for the estimation of total chlorophyll concentration when

448 there are limits on available instruments or, for example, using two-band LED sensors

449 (e.g., Garrity et al. 2010; Ryu et al. 2010). The result also has implications for the current

450 and future use of field spectrometers that measure leaf or canopy reflectance at high

451 temporal frequency (e.g., Hilker et al. 2009). Our well-calibrated PLSR models can be

452 used on leaf reflectance to track the seasonality of multiple leaf traits in temperate 453 deciduous forests. 
The tests on the robustness of leaf spectra-trait relationships suggested that the

455 overlap between the training dataset and an independent validation dataset is important

456 for a good prediction. Traditionally, the development of the leaf traits-spectra relationship

457 has been focused on a single time point, typically mid-season and mature leaves. Summer

458 mature leaves displayed higher pigments concentration and LMA, while lower $\mathrm{N}_{\text {mass }}$

459 compared with young leaves (Fig. 1, Fig. 2). In addition, the corresponding leaf spectra

460 were significantly different (Fig. 4). We have shown here that if we apply an empirical

461 relationship between spectra and traits derived from one period (for example, summer) to

462 another (spring or fall), leaf traits will likely be over or under-estimated (Fig. S4-S6).

463 These findings mirror that observed by McKown et al., (2013) which used traditional trait

464 measurements across key phenophases of a temperate forest species, Populus trichocarpa,

465 to show that the direction and magnitude of many trait-trait relationships is strongly tied

466 to phenological state and can change over a season. However, we have also illustrated

467 that with proper calibration, we can adequately characterize the seasonality of a range of

468 leaf traits, despite the impacts of phenology, which is critical for monitoring ecosystems

469 and informing large-scale modeling activities (Table 5).

470 VIP values can help to explain the prediction power of PLSR models. For

471 example, in the case of PLSR models trained with data from one site to predict another

472 (Test $1 \& 2$ ), VIP values of leaf pigments overlap well, indicating both sites share similar

473 wavelength regions (Fig. S11). As a result, cross-site prediction of leaf pigments showed

474 reasonable accuracy (Table 5). It also has important implications for the design of multi-

475 band sensors and imagers as it can select the wavelengths that are most useful for the leaf

476 traits of interest (Nijland et al. 2014; Ryu et al. 2010). 
478 absorption features of pigments are well understood and clearly represented in the VIP 479 value plots (Fig. 6). While for $\mathrm{C}_{\text {mass }}$ and $\mathrm{N}_{\text {mass, }}$, although there have been studies on the 480 possible linkage between certain components in the leaves (e.g., protein, cellulose) and 481 leaves' optical properties, the impact on leaf spectra is is less pronounced in any single 482 spectral range as compared with pigments and instead is more generally spread across the 483 visible and shortwave infrared spectral regions (Curran, 1989; Kokaly et al., 2009). This 484 may partly explain the less accurate PLSR models for the $\mathrm{C}_{\text {mass }}$ and $\mathrm{N}_{\text {mass }}$. Moreover, in 485 fresh leaves the spectral absorption by proteins can be partially obscured by water 486 absorption, which can impact the performance of statistical (e.g. PLSR, SVIs) and other 487 spectral inversion approaches, such as radiative transfer models (RTMs).

488 As expected, the PLSR approach, which can exploit the full spectrum information 489 to estimate leaf traits performed better than traditional SVIs (Table 3). While SVIs that 490 were calibrated with extensive datasets displayed a similar performance to PLSR in 491 estimating total chlorophyll concentration, we observed better performance of PLSR for 492 the carotenoids and LMA. Calibrating SVIs with our own datasets did not improve their 493 performance. In addition, we calculated the correlation coefficient (r) of all possible two494 band SVIs with total chlorophyll, carotenoids, and LMA (Fig. S13). We found that the 495 highest correlation (in terms of the absolute value of $r$ ) between the SVIs and three leaf 496 traits are $-0.8,-0.7$, and -0.65 , respectively. This suggests that the variability of leaf traits 497 in our dataset was not fully captured by the SVIs, despite that our dataset covering a 498 broad ranges of values observed by others (Féret et al. 2011). Incorporating more datasets 499 to the calibration of simple indices could potentially improve the performance of these 
500 methods, but will not alleviate the saturation issue that is pervasive when using simple

501 SVIs, especially for LMA.

502 As the applications of leaf spectra-traits relationship become more common, we

503 argue that a standardized protocol to calibrate and validate PLSR-type models is needed.

504 This includes independent validation to avoid evaluating model performance against the

505 calibration dataset itself and a method to choose the optimal number of PLSR

506 components to prevent overfitting (Serbin et al. 2014; Wu et al., 2016b). A globally

507 relevant algorithm for leaf traits that can be used by ground spectral observations (Hilker

508 et al. 2010), upcoming (e.g., EnMAP; Guanter et al., 2015) or existing or planned satellite

509 missions such as NASA's HyspIRI mission (such as https://hyspiri.jpl.nasa.gov/; Lee et

510 al., 2015) hinges on a rigorously-tested method and on datasets covering a wide range of

511 variations in leaf traits.

512

$513 \quad 4.2$ The implications for field sampling strategy

514 The time-series of leaf traits we presented here showed the critical time windows

515 to capture trait seasonality. These patterns are similar to observations on other temperate

516 species (e.g. McKown et al., 2013). Extensive field sampling is laborious and expensive

517 and the continual question in plant ecology is "how much is good enough?" Since the

518 measurements of leaf spectral properties are less labor-intensive (and non-destructive)

519 compared with the measurements of most leaf traits, we explored how many destructive

520 measurements of leaf traits were needed to calibrate the models using full leaf spectra.

521 For example, LMA showed dramatic changes in the early season, thus the sampling and

522 calibration process needs to include the data at this critical phenophase (Fig. 2a). 
523 Similarly, $\mathrm{N}_{\text {mass }}$ was relatively stable in the mid season, and most of the variations

524 occurred in the beginning and end of season, which makes the sampling at these time

525 points important (Fig. 2b). This explains why our comparisons that only considered the

526 variability of leaf traits in the summer showed poorer performance, as compared to a

527 model capturing the full seasonal variability Therefore, monthly and even biweekly

528 sampling should be considered, at least for the four temperate deciduous species

529 examined in this study.

530

5314.3 Broad implications of using leaf spectroscopy for ecological studies

532 Understanding the seasonality of leaf traits has recently gained attention as an

533 effort to improve our modeling of terrestrial carbon and water cycles (Bauerle et al. 2012;

534 Grassi et al. 2005; Medvigy et al. 2013). For example, in the Community Land Model,

$535 \mathrm{~N}_{\text {mass }}$ and LMA control the maximum rate of carboxylation, $\mathrm{V}_{\mathrm{cmax}}$, which is highly

536 variable temporally and across different species and light environments (Oleson et al.,

537 2013). Our time-series of $\mathrm{N}_{\text {mass }}$ capture two important features: (1) the seasonal peak at

538 the beginning of the spring, suggesting that nitrogen was allocated to the leaves early in

539 the season. As leaves matured, other types of elements such as carbon accumulated at a

540 faster rate, resulting in an increase of $C_{\text {mass }}$ relative to $N_{\text {mass }}$ ratio. (2) A decline of $N_{\text {mass }}$

541 by the end of the season. $\mathrm{N}_{\text {mass }}$ and LMA was relatively stable at both sites during the

542 summer (Fig. 2a and 2b), thus leaf age does not appear to be affecting the nitrogen

543 concentration during the peak season (Field and Mooney 1983). This finding as that of

544 others (Wilson et al. 2000; McKown et al., 2013) highlights the importance of tracking

545 the seasonality of leaf traits, and our work demonstrates that leaf spectroscopy can 
546 provide a rapid means to routinely measure leaf traits. Importantly, these results highlight

547 that spectroscopy observations can provide key information on the individual differences

548 in multiple leaf traits that can feed into ecosystem models (Medvigy et al., 2009) or be

549 used to test key ecological hypotheses (Rowland et al., 2015). Our results suggest the

550 important capability of monitoring ecosystem dynamics across a range of spatial and

551 temporal scales with hyperspectral observations from leaves, towers, as well as with new

552 instruments mounted on unmanned and piloted aircraft and satellite platforms (Yang et

553 al., 2014; Yang et al., 2015; Asner and Martin, 2008; Hilker et al., 2010).

555 5. Conclusion

556 This paper presents a comprehensive study of the relationship between leaf 557 spectra and foliar traits across varying leaf developmental stages, sites, and light 558 environment using a near weekly dataset of seven leaf traits and spectra at two sites. A

559 Partial Least Square Regression (PLSR) modeling approach, after proper calibration with

560 leaf traits from different times of the season, showed a strong capacity to quantify the

561 seasonal variation of leaf traits within and across sites. The robustness of a PLSR model

562 largely depends on the overlap of leaf trait ranges between the calibration dataset and the

563 dataset to be estimated, and extrapolation outside the ranges of the calibration dataset can

564 result in a significant error. We found that biweekly sampling of leaf traits and spectra

565 would provide a robust PLSR model to estimate the seasonal variations of leaf traits. This

566 work demonstrated the capability of leaf spectra to track seasonally varying leaf traits,

567 and thus supports the use of automated field spectrometers, airborne and satellite 
568 hyperspectral sensors to track leaf traits repeatedly throughout the season and across

569 broad regions (Roberts et al. 2012; Singh et al., 2015; Yang et al. 2015).

\section{Acknowledgements}

572 We thank Katie Laushman, Lakiah Clark, Skyler Hackley, Rui Zhang, Kate Morkeski,

573 Mengdi Cui, Marc Mayes and Tim Savas for assisting with fieldwork. We thank Matthew

574 Erickson, Marshall Otter, Rich McHorney, Jane Tucker and Sam Kelsey from the Marine

575 Biological Laboratory for the help with labwork. We also thank the Harvard Forest, the

576 Manuel F. Correllus State Forest, Nature's Conservancy Hoft Farm Preserve and Mr.

577 Colbert for the permission to use the forests for research. This research was supported by

578 the Brown University-Marine Biological Laboratory graduate program in Biological and

579 Environmental Sciences, and Marine Biological Laboratory start-up funding for JT. JT

580 was also partially supported by the U.S. Department of Energy (DOE) Office of

581 Biological and Environmental Research grant DE-SC0006951 and the National Science

582 Foundation grants DBI-959333 and AGS-1005663. SPS was supported in part by the U.S.

583 DOE contract No. DE-SC00112704 to Brookhaven National Laboratory. JW was

584 supported by the NASA Earth and Space Science Fellowship (NESSF2014).

\section{Reference}

591 Scaling from leaf to canopy levels. Remote Sensing of Environment, 112, 3958-3970

592 Asner, G.P., Martin, R.E., Ford, A., Metcalfe, D., \& Liddell, M. (2009). Leaf chemical

593 and spectral diversity in Australian tropical forests. Ecological Applications, 19, 236-253 
594 Asner, G.P., Martin, R.E., Knapp, D.E., Tupayachi, R., Anderson, C., Carranza, L., 595 Martinez, P., Houcheime, M., Sinca, F., \& Weiss, P. (2011). Spectroscopy of canopy 596 chemicals in humid tropical forests. Remote Sensing of Environment, 115, 3587-3598

597 Asner, G.P., \& Vitousek, P.M. (2005). Remote analysis of biological invasion and 598 biogeochemical change. Proc Natl Acad Sci U S A, 102, 4383-4386

599 Bauerle, W.L., Oren, R., Way, D.A., Qian, S.S., Stoy, P.C., Thornton, P.E., Bowden, 600 J.D., Hoffman, F.M., \& Reynolds, R.F. (2012). Photoperiodic regulation of the seasonal 601 pattern of photosynthetic capacity and the implications for carbon cycling. Proceedings

602 of the National Academy of Sciences, 109, 8612-8617

603 Belanger, M., Miller, J., \& Boyer, M. (1995). Comparative relationships between some 604 red edge parameters and seasonal leaf chlorophyll concentrations. Canadian Journal of 605 Remote Sensing, 21, 16-21

606 Bonan, G.B., Oleson, K.W., Fisher, R.A., Lasslop, G., \& Reichstein, M. (2012).

607 Reconciling leaf physiological traits and canopy flux data: Use of the TRY and

608 FLUXNET databases in the Community Land Model version 4. Journal of Geophysical

609 Research: Biogeosciences, 117, G02026.

610 Chapin, F.S., Matson, P.A., \& Vitousek, P.M. (2011). Principles of terrestrial ecosystem 611 ecology. (2nd Edition ed.). Springer

612 Couture, J.J., Serbin, S.P., \& Townsend, P.A. (2013). Spectroscopic sensitivity of real613 time, rapidly induced phytochemical change in response to damage. New Phytologist, $614198,311-319$.

615 Curran, P.J. (1989). Remote sensing of foliar chemistry. Remote Sensing of Environment, $61630,271-278$

617 Demmig-Adams, B., \& Adams, W.W. (2000). Photosynthesis: Harvesting sunlight

618 safely. Nature, 403, 371-374

619 Dillen, S.Y., de Beeck, M.O., Hufkens, K., Buonanduci, M., \& Phillips, N.G. (2012). 620 Seasonal patterns of foliar reflectance in relation to photosynthetic capacity and color 621 index in two co-occurring tree species, Quercus rubra and Betula papyrifera. Agricultural 622 and Forest Meteorology, 160, 60-68

623 Eckstein, R.L., Karlsson, P.S., \& Weih, M. (1999). Leaf life span and nutrient resorption 624 as determinants of plant nutrient conservation in temperate-arctic regions. New 625 Phytologist, 143, 177-189

626 Ellsworth, D.S., \& Reich, P.B. (1993). Canopy structure and vertical patterns of 627 photosynthesis and related leaf traits in a deciduous forest. Oecologia, 96, 169-178

628 Elvidge, C.D. (1990). Visible and near infrared reflectance characteristics of dry plant 629 materials. International Journal of Remote Sensing, 11, 1775-1795 
630 Evans, J. (1989). Photosynthesis and nitrogen relationships in leaves of C3 plants.

631 Oecologia, 78, 9-19

632 Evans, J. (1989b). Partitioning of nitrogen between and within leaves grown under

633 different irradiances. Australian Journal of Plant Physiology 16(6): 533-548.

634 Féret, J.-B., François, C., Gitelson, A., Asner, G.P., Barry, K.M., Panigada, C.,

635 Richardson, A.D., \& Jacquemoud, S. (2011). Optimizing spectral indices and

636 chemometric analysis of leaf chemical properties using radiative transfer modeling.

637 Remote Sensing of Environment, 115, 2742-2750

638 Field, C., \& Mooney, H.A. (1983). Leaf age and seasonal effects on light, water, and

639 nitrogen use efficiency in a California shrub. Oecologia, 56, 348-355

640 Fisher, J., \& Mustard, J. (2007). Cross-scalar satellite phenology from ground, Landsat,

641 and MODIS data. Remote Sensing of Environment, 109, 261-273

642 Foster, D., Hall, B., Barry, S., Clayden, S., \& Parshall, T. (2002). Cultural, environmental

643 and historical controls of vegetation patterns and the modern conservation setting on the

644 island of Martha's Vineyard, USA. Journal of Biogeography, 29, 1381-1400

645 Garrity, S.R., Vierling, L.A., \& Bickford, K. (2010). A simple filtered photodiode

646 instrument for continuous measurement of narrowband NDVI and PRI over vegetated

647 canopies. Agricultural and Forest Meteorology, 150, 489-496

648 Grassi, G., Vicinelli, E., Ponti, F., Cantoni, L., \& Magnani, F. (2005). Seasonal and

649 interannual variability of photosynthetic capacity in relation to leaf nitrogen in a

650 deciduous forest plantation in northern Italy. Tree Physiol, 25, 349-360

651 Hilker, T., Coops, N.C., Coggins, S.B., Wulder, M.A., Brownc, M., Black, T.A., Nesic, 652 Z., \& Lessard, D. (2009). Detection of foliage conditions and disturbance from multi-

653 angular high spectral resolution remote sensing. Remote Sensing of Environment, 113,

$654 \quad 421-434$

655 Hilker, T., Nesic, Z., Coops, N.C., \& Lessard, D. (2010). A New, Automated,

656 Multiangular Radiometer Instrument for Tower-Based Observations of Canopy

657 Reflectance (Amspec Ii). Instrumentation Science \& Technology, 38, 319-340

658 Huete, A., Didan, K., Miura, T., Rodriguez, E.P., Gao, X., \& Ferreira, L.G. (2002).

659 Overview of the radiometric and biophysical performance of the MODIS vegetation

660 indices. Remote Sensing of Environment, 83, 195-213

661 Jacquemoud, S., \& Baret, F. (1990). PROSPECT: A model of leaf optical properties

662 spectra. Remote Sensing of Environment, 34, 75-91

663 Kattge, J., Díaz, S., Lavorel, S., Prentice, I.C., Leadley, P., Bönisch, G., Garnier, E.,

664 Westoby, M., Reich, P.B., Wright, I.J. et al., (2011). TRY - a global database of plant

665 traits. Global Change Biology, 17, 2905-2935 
666 Kennard, R.W., \& Stone, L.A. (1969). Computer Aided Design of Experiments.

667 Technometrics, 11, 137-148

668 Killingbeck, K.T. (1996). Nutrients in Senesced Leaves: Keys to the Search for Potential 669 Resorption and Resorption Proficiency. Ecology, 77, 1716-1727

670 Kokaly, R.F., Asner, G.P., Ollinger, S.V., Martin, M.E., \& Wessman, C.A. (2009).

671 Characterizing canopy biochemistry from imaging spectroscopy and its application to

672 ecosystem studies. Remote Sensing of Environment, 113, S78-S91

673 Laisk, A., Nedbal, L., \& Govindjee (2009). Photosynthesis in silico: understanding

674 complexity from molecules to ecosystems. Springer Science \& Business Media

675 Lewandowska, M., \& Jarvis, P. (1977). Changes in chlorophyll and carotenoid content, 676 specific leaf area and dry weight fraction in Sitka spruce, in response to shading and 677 season. New Phytologist, 79, 247-256

678 Lichtenthaler, H.K., \& Buschmann, C. (2001). Chlorophylls and Carotenoids:

679 Measurement and Characterization by UV-VIS Spectroscopy. Current Protocols in Food 680 Analytical Chemistry: John Wiley \& Sons, Inc.

681 McKown, A.D., Guy, R.D., Azam, M.S., Drewes, E.C., \& Quamme, L.K. (2013).

682 Seasonality and phenology alter functional leaf traits. Oecologia, 172, 653-665

683 Medvigy, D., S. C. Wofsy, J. W. Munger, D. Y. Hollinger, and P. R. Moorcroft. (2009)

684 Mechanistic scaling of ecosystem function and dynamics in space and time: Ecosystem

685 Demography model version 2. Journal of Geophysical Research - Biogeosciences, 114, 686 G01002, doi:10.1029/2008JG000812.

687 Medvigy, D., Jeong, S.-J., Clark, K.L., Skowronski, N.S., \& Schäfer, K.V.R. (2013).

688 Effects of seasonal variation of photosynthetic capacity on the carbon fluxes of a

689 temperate deciduous forest. Journal of Geophysical Research: Biogeosciences, 118,

$690 \quad 1703-1714$

691 Mehmood, T., Liland, K.H., Snipen, L., \& Sæbø, S. (2012). A review of variable

692 selection methods in Partial Least Squares Regression. Chemometrics and Intelligent

693 Laboratory Systems, 118, 62-69

694 Niinemets U. 2007. Photosynthesis and resource distribution through plant canopies.

695 Plant Cell and Environment 30(9): 1052-1071.

696 Nijland, W., de Jong, R., de Jong, S.M., Wulder, M.A., Bater, C.W., \& Coops, N.C.

697 (2014). Monitoring plant condition and phenology using infrared sensitive consumer

698 grade digital cameras. Agricultural and Forest Meteorology, 184, 98-106

699 Oleson, K.W., D.M. Lawrence, G.B. Bonan, et al., 2013: Technical Description of

700 version 4.5 of the Community Land Model (CLM). Ncar Technical Note NCAR/TN-

$701503+$ STR, National Center for Atmospheric Research, Boulder, CO, DOI:

702 10.5065/D6RR1W7M. 
Ollinger, S.V. (2011). Sources of variability in canopy reflectance and the convergent properties of plants. New Phytologist, 189, 375-394

Poorter, H., Niinemets, Ü., Poorter, L., Wright, I.J., \& Villar, R. (2009). Causes and consequences of variation in leaf mass per area (LMA): a meta-analysis. New Phytologist, 182, 565-588

708 Richardson, A.D., Duigan, S.P., \& Berlyn, G.P. (2002). An evaluation of noninvasive methods to estimate foliar chlorophyll content. New Phytologist, 153, 185-194

710 Roberts, D.A., Quattrochi, D.A., Hulley, G.C., Hook, S.J., \& Green, R.O. (2012).

711 Synergies between VSWIR and TIR data for the urban environment: An evaluation of the 712 potential for the Hyperspectral Infrared Imager (HyspIRI) Decadal Survey mission.

713 Remote Sensing of Environment, 117, 83-101

714 Rowland, L., et al. (2015), Death from drought in tropical forests is triggered by

715 hydraulics not carbon starvation, Nature, 528(7580), 119-122, doi:10.1038/nature15539.

716 Ryu, Y., Baldocchi, D.D., Verfaillie, J., Ma, S., Falk, M., Ruiz-Mercado, I., Hehn, T., \&

717 Sonnentag, O. (2010). Testing the performance of a novel spectral reflectance sensor,

718 built with light emitting diodes (LEDs), to monitor ecosystem metabolism, structure and

719 function. Agricultural and Forest Meteorology, 150, 1597-1606

720 Schimel, D., Pavlick, R., Fisher, J.B., Asner, G.P., Saatchi, S., Townsend, P., Miller, C., 721 Frankenberg, C., Hibbard, K., \& Cox, P. (2015). Observing terrestrial ecosystems and the 722 carbon cycle from space. Global Change Biology, 21, 1762-1776

723 Schneider, C.A., Rasband, W.S., \& Eliceiri, K.W. (2012). NIH Image to ImageJ: 25 years

724 of image analysis. Nature Methods, 9, 671-675

725 Serbin, S.P., Singh, A., McNeil, B.E., Kingdon, C.C., \& Townsend, P.A. (2014).

726 Spectroscopic determination of leaf morphological and biochemical traits for northern

727 temperate and boreal tree species. Ecological Applications, 24, 1651-1669

728 Shen, M., Chen, J., Zhu, X., \& Tang, Y. (2009). Yellow flowers can decrease NDVI and

729 EVI values: evidence from a field experiment in an alpine meadow. Canadian Journal of

730 Remote Sensing, 35, 99-106

731 Sims, D.A., \& Gamon, J.A. (2002). Relationships between leaf pigment content and 732 spectral reflectance across a wide range of species, leaf structures and developmental 733 stages. Remote Sensing of Environment, 81, 337-354

734 Singh, A., Serbin, S.P., McNeil, B.E., Kingdon, C.C., \& Townsend, P.A. (2015). Imaging 735 spectroscopy algorithms for mapping canopy foliar chemical and morphological traits 736 and their uncertainties. Ecological Applications

737 Terashima, I., Miyazawa, S.-I., \& Hanba, Y.T. (2001). Why are sun leaves thicker than 738 shade leaves? - Consideration based on analyses of $\mathrm{CO} 2$ diffusion in the leaf. J Plant 739 Res, 114, 93-105 
Ustin, S.L., Gitelson, A.A., Jacquemoud, S., Schaepman, M., Asner, G.P., Gamon, J.A., $\&$ Zarco-Tejada, P. (2009). Retrieval of foliar information about plant pigment systems from high resolution spectroscopy. Remote Sensing of Environment, 113, S67-S77

743 Ustin, S.L., Roberts, D.A., Gamon, J.A., Asner, G.P., \& Green, R.O. (2004). Using 744 imaging spectroscopy to study ecosystem processes and properties. Bioscience, 54, 523$745 \quad 534$

746 Wicklein, H.F., Ollinger, S.V., Martin, M.E., Hollinger, D.Y., Lepine, L.C., Day, M.C., Bartlett, M.K., Richardson, A.D., \& Norby, R.J. (2012). Variation in foliar nitrogen and albedo in response to nitrogen fertilization and elevated CO2. Oecologia, 169, 915-925

758 Wofsy, S.C., Goulden, M.L., Munger, J.W., Fan, S.-M., Bakwin, P.S., Daube, B.C.,

Wilson, K.B., Baldocchi, D.D., \& Hanson, P.J. (2000). Spatial and seasonal variability of photosynthetic parameters and their relationship to leaf nitrogen in a deciduous forest. Tree Physiol, 20, 565-578

Wu, J., Albert, L.P., Lopes, A.P., Restrepo-Coupe, N., Hayek, M., Wiedemann, K.T., Guan, K., Stark, S.C., et al. (2016). Leaf development and demography explain photosynthetic seasonality in Amazon evergreen forests. Science, 351, 972-976.

Wu, J., Chavana-Bryant, C., Prohaska, N., Serbin, S.P., Guan, K., Albert, L.P., Yang, X., et al. (2016b) Convergence in relations among leaf traits, spectra and ages across diverse canopy environments and two contrasting tropical forests. New Phytologist. Accepted.

761 Wold, S., Sjöström, M., \& Eriksson, L. (2001). PLS-regression: a basic tool of

762 chemometrics. Chemometrics and Intelligent Laboratory Systems, 58, 109-130

763 Wright, I.J., Reich, P.B., Westoby, M., Ackerly, D.D., Baruch, Z., Bongers, F., 764 Cavender-Bares, J., Chapin, T., et al. (2004). The worldwide leaf economics spectrum. 765 Nature, $428,821-827$

766 Yang, X., Mustard, J., Tang, J., \& Xu, H. (2012). Regional-scale phenology modeling based on meteorological records and remote sensing observations. J. Geophys. Res., 117,

768 G03029

769 Yang, X., Tang, J., \& Mustard, J. (2014). Beyond leaf color: comparing camera-based 770 phenological metrics with leaf biochemical, biophysical and spectral properties 771 throughout the growing season of a temperate deciduous forest. Journal of Geophysical 772 Research: Biogeosciences, 119, 181-191.

773 Yang, X., Tang, J., Mustard, J.F., Lee, J.-E., Rossini, M., Joiner, J., Munger, J.W., 774 Kornfeld, A., \& Richardson, A.D. (2015). Solar-induced chlorophyll fluorescence that 775 correlates with canopy photosynthesis on diurnal and seasonal scales in a temperate 776 deciduous forest. Geophysical Research Letters, 42, 2977-2987 
777 Zhang, Y., Chen, J.M., \& Thomas, S.C. (2007). Retrieving seasonal variation in 778 chlorophyll content of overstory and understory sugar maple leaves from leaf-level 779 hyperspectral data. Canadian Journal of Remote Sensing, 33, 406-415

780 Zhao, K., Valle, D., Popescu, S., Zhang, X., \& Mallick, B. (2013). Hyperspectral remote 781 sensing of plant biochemistry using Bayesian model averaging with variable and band 782 selection. Remote Sensing of Environment, 132, 102-119 